\title{
Bundle Branch and Atrioventricular Block as Complications of Acute Myocardial Infarction in the Thrombolytic Era
}

\author{
Claudia Caminha Escosteguy, Marciano de Almeida Carvalho, Roberto de Andrade Medronho, \\ Luiz Maurino Abreu, Mario Ypiranga Monteiro Filho \\ Rio de Janeiro, RJ - Brazil
}

\begin{abstract}
Objective - To analyze the incidence of intraventricular and atrioventricular conduction defects associated with acute myocardial infarction and the degree of in hospital mortality resulting from this condition during the era of thrombolytic therapy.
\end{abstract}

Methods - Observational study of a cohort of 929 consecutive patients with acute myocardial infarction. Multivariate analysis by logistic regression. Was used.

Results - Logistic regression showed a greater incidence of bundle branch block in male sex (odds ratio $=$ $1.87,95 \% C I=1.02-3.42$ ), age over 70 years (odds ratio $=$ $2.31,95 \% C I=1.68-5.00)$, anterior localization of the infarction (odds ratio $=1.93,95 \% C I=1.03-3.65$ ). There was a greater incidence of complete atrioventricular block in inferior infarcts (odds ratio $=2.59,95 \%$ CI 1.305.18) and the presence of cardiogenic shock (odds ratio $=$ $3.90,95 \%$ CI $=1.43-10.65)$. Use of a thrombolytic agent was associated with a tendency toward a lower occurrence of bundle branch block (odds ratio $=0.68$ ) and a greater occurrence of complete atrioventricular block (odds ratio $=1.44$ ). The presence of bundle branch block (odds ratio $=2.4595 \%, C I=1.14-5.28)$ and of complete atrioventricular block (odds ratio $=13.59,95 \% C I=5.43$ 33.98) was associated with a high and independent probability of inhospital death.

Conclusion - During the current era of thrombolytic therapy and in this population, intraventricular disturbances of electrical conduction and complete atrioventricular block were associated with a high and independent risk of inhospital death during acute myocardial infarction.

Key words: Bundle branch block, complete atrioventricular block, thrombolysis

Hospital dos Servidores do Estado do Rio de Janeiro

Mailing address: Claudia Caminha Escosteguy - Av. Alexandre Ferreira, 361 22470-220 - Rio de Janeiro, RJ - Brazil
Studies from the pre thrombolytic era have shown that intraventricular and atrioventricular conduction defects were associated with a greater inhospital morbidity and mortality in patients with acute myocardial infarction ${ }^{1-5}$.

The impact of thrombolytic therapy on acute myocardial infarction mortality has been widely confirmed by scientific evidence. Yet, the majority of controlled clinical studies on thrombolysis do not refer to the incidence of and mortality from atrial and interventricular conduction disturbances; few studies explicitly compare these variables between pre- and postthrombolytic therapy eras ${ }^{6,7}$. A few literature reports have suggested that reperfusion of an artery related to the infarction can lower the incidence of conduction disturbances, because thrombolysis decreases the size of the infarction ${ }^{8}$; others have suggested that the appearance of complete atrioventricular block may be signaling successful reperfusion ${ }^{9}$. However, the prognosis associated with intraventricular and atrioventricular conduction disturbances has been viewed with reserve during this era of thrombolytic therapy ${ }^{7,10-12}$.

In Brazil, information on this theme is scanty ${ }^{13}$. Aiming at the improvement of knowledge about this issue, the present study has the objective of describing intraventricular and atrioventricular conduction disturbances in acute myocardial infarction in a public coronary unit in Rio de Janeiro in the thrombolytic era, as well as the associated inhospital mortality.

\section{Methods}

The hospital phase of a cohort of 929 consecutive patients with acute myocardial infarction admitted between 1987 and 1992 to the coronary unit of the Public Servants Hospital of the State of Rio de Janeiro was studied.

Acute myocardial infarction was diagnosed on the basis of the triad of clinical history, new electrocardiographic alterations, and cardiac serum enzyme levels. Diagnostic criteria have been reported elsewhere ${ }^{14,15}$.

The following conduction disturbances were analy- 
zed: any degree of right branch block; any degree of left branch block; left anterior hemiblock, posterior hemiblock; Mobitz $1^{\text {st }}$ and $2^{\text {nd }}$ degree atrioventricular block, and $3^{\text {rd }}$ or complete atrioventricular block. For right and left branch block and complete atrioventricular block, the diagnostic criterion was electrocardiographic as proposed by the New York Heart Association (NYHA) ${ }^{14}$ and for the subdivisions of the left branch, criteria used were those of Rosenbaum et al. ${ }^{16,17}$. The same diagnostic criteria were followed throughout the period of study.

For statistical analysis, $\chi^{2}$, Fisher's exact test, odds ratio calculations, and $95 \%$ confidence intervals $(\mathrm{CI})$ were used. Logistic regression was used for multivariate analysis. P values higher than 0.05 were considered nonsignificant.

\section{Results}

Of 929 cases, $644(69.3 \%)$ were men and $285(30.7 \%)$ were women; the average age was $59.9 \pm 15.2$ years. Infarcts were anterior in $47.7 \%$, inferior in $47.9 \%$, and non Q wave in $6.4 \%$ of the patients. Intravenous thrombolysis was performed in 179 (19.3\%) cases. Streptokinase was used in $63.6 \%$ of the cases; rt-PA in $36.4 \%$. The thrombolysis protocol used was that of The Consensus of the Brazilian Society of Cardiology ${ }^{18}$, noting that at the period studied, rt-PA accelerated infusion was not yet being used.

The percentage of thrombolysis increased during the period studied: in 1987, the year of the establishment of the thrombolysis program, it was lowest at 3.6\%; in 1988 it increased to $10.7 \%$, and from 1989 on it was always above $25 \%$, oscillating between 25.5 and $34.6 \%$ of the patients with acute myocardial infarct admitted to the coronary unit. The maximum percentage was reached in 1990 . It is worth pointing out that from 1989 on, loss of the opportunity to perform thrombolysis in cases where this was indicated was an exceptional occurrence, being actually used as a sentinel for the evaluation of the assistance rendered by the unit. Thus from 1989 onwards, the fluctuation observed in the percentage of thrombolysis therapy used was basically attributed to a variation in the profile of the cases admitted. The most frequent cause of the nonperformance of thrombolysis was the high time (above 12h) of infarct evolution that was related mainly to the attended patient' s profile.

Cases not receiving thrombolytic agents underwent conventional treatment, including aspirin, beta-blockers, nitrate, and heparin, counterindications being respected. Patients who underwent thrombolysis received coadjutant therapy, intravenously in the case of heparin, and subcutaneously in the case of streptokinase. The use of angiotensin-converting enzyme inhibitors had not become routine at the time of this study.

Inhospital mortality of the cohort studied was $12.6 \%$ (117 cases).

Table I shows the incidence of and degree of inhospital mortality associated with various types of intraventricular and atrioventricular block. Association of bundle branch block also is specified; in other cases, bundle branch block was an isolated event. During the evolution of some cases, the same patient experienced $2^{\text {nd }}$ degree atrioventricular block with complete atrioventricular block or bundle branch block and complete atrioventricular block (Table I).

When considering any right bundle branch block, whether isolated or associated with hemiblock, the incidence ratio was of $5.1 \%$. The category "any bundle branch block" refers to any type of bundle branch block (right or left) associated or not with hemiblock. Twenty additional cases of anterior left isolated hemiblock (2.2\% incidence) with three $(15 \%)$ fatalities were observed.

Information on the beginning of the block was obtained in 832 (89.6\% of the cases); $76.3 \%$ were acute, $14.8 \%$ preexisting, and in $8.9 \%$ the date of onset was indeterminate. All cases of complete atrioventricular block were acute (Table II).

Table III presents the incidence of different types of block according to the localization of the infarct. Association of intraventricular block with the anterior localization and of the atrioventricular block with the inferior localization, respectively, was observed. The incidence of left bundle branch block tended to be greater in acute inferior myocardial infarction, although this correlation was not significant, possibly because $21.1 \%$ of the left bundle branch blocks were preexisting.

Table III does not include cases of acute myocardial infarction of the type without $Q$, described below, with their

\begin{tabular}{|lcccc|}
\hline \multicolumn{4}{|c|}{ Table I - Incidence and mortality of block in 929 cases of acute } \\
myocardial infarction
\end{tabular}

\begin{tabular}{|c|c|c|c|}
\hline \multicolumn{4}{|c|}{$\begin{array}{c}\text { Table II - Percentage distribution at the beginning of acute } \\
\text { myocardial infarction block }\end{array}$} \\
\hline \multirow[b]{2}{*}{ Block } & \multicolumn{3}{|c|}{ Beginning of block } \\
\hline & Acute & Previous & Indeterminate \\
\hline RBB & 50.0 & 21.4 & 28.6 \\
\hline $\mathrm{RBB}+\mathrm{LAHB}$ or $\mathrm{PHB}$ & 57.1 & 25.0 & 17.9 \\
\hline LBB & 57.9 & 21.1 & 21.1 \\
\hline CAVB & 100 & 0 & 0 \\
\hline Any above block & 76.3 & 14.8 & 8.9 \\
\hline \multicolumn{4}{|c|}{$\begin{array}{l}\text { RBB- right branch block; LAHB- left anterior hemiblock; LBB- left branch } \\
\text { block; PHB- posterior hemiblock; CAVB- complete atrioventricular block; } \\
\text { AVB- atrioventricular block. }\end{array}$} \\
\hline
\end{tabular}




\begin{tabular}{|lccc|}
\hline \multicolumn{4}{|c|}{ Table III - Incidence of block according to the localization of the } \\
acute myocardial infarction
\end{tabular}

respective incidences: right branch block + left anterior hemiblock -1 case $(1.7 \%)$; left branch block -2 cases (3.4\%); complete atrioventricular block-1 case (1.7\%).

The change of the occurrence of block in the population studied was analyzed next, using the multivariate logistic model. Table IV shows the odds ratio adjusted by the occurrence of any branch block (left or right branch block, associated or not to hemiblock), in a logistic model with a $\mathrm{P}=0.0001$ (-2LOGL) adjustment and a concordance of $65.4 \%$. In view of the reduced number of each isolated type, grouped analysis of branch block was chosen. The following were among the variables studied that had independent, significant association with a greater occurrence of branch block: patient over 70 years of age; anterior localization of the acute myocardial infarction and heart failure (defined by classes Killip II, III or IV) in acute phase. Reference categories were, respectively: age equal to or less than 70 years, other localization of the acute myocardial infarction, and absence of heart failure (Killip I). Compared with males, the females had a lower significant chance of the occurrence of bundle branch block.

Table $\mathrm{V}$ provides an analysis of the chance of the development of complete atrioventricular block, estimated by the logistic model with adjustment at $\mathrm{P}=0.0001$ (-2LOG L) and $64.8 \%$, for some variables. Significant positive associations with the development of atrioventricular block were inferior localization of the infarction and the presence of

\begin{tabular}{|lcccc|}
\hline \multicolumn{5}{|c|}{ Table IV $\begin{array}{c}\text { - Risk of occurrence of bundle branch block estimated } \\
\text { by odds ratio adjusted by the logistic model }\end{array}$} \\
\hline Variable & $\begin{array}{l}\text { Odds } \\
\text { ratio }\end{array}$ & $\begin{array}{c}\text { 95\% CI Limits } \\
\text { Inferior }\end{array}$ & Superior & $p$ \\
& 0.54 & 0.29 & 0.98 & 0.04 \\
Female Sex & 2.31 & 1.33 & 4.04 & 0.003 \\
Age >70 years & 2.90 & 1.68 & 5.00 & 0.0001 \\
Anterior wall & 1.93 & 1.03 & 3.65 & 0.04 \\
HF(Killip II to IV) & 0.68 & 4.29 & NS \\
Recurrent ischemia & 1.71 & 0.32 & 1.44 & NS \\
Thrombolysis & 0.68 & 0.32 & \\
\hline
\end{tabular}

\begin{tabular}{|c|c|c|c|c|}
\hline \multicolumn{5}{|c|}{$\begin{array}{c}\text { Table } V \text { - Risk of development of complete atrioventricular } \\
\text { block estimated by odds ratios adjusted by the logistic } \\
\text { model }\end{array}$} \\
\hline \multirow[t]{2}{*}{ Variable } & \multirow{2}{*}{$\begin{array}{l}\text { Odds } \\
\text { ratio }\end{array}$} & \multicolumn{2}{|c|}{ 95\% CI Limits } & \multirow[t]{2}{*}{$p$} \\
\hline & & Inferior & Superior & \\
\hline Female sex & 0.65 & 0.30 & 1.41 & NS \\
\hline Age $>70$ years & 1.50 & 0.71 & 3.16 & NS \\
\hline Inferior wall & 2.59 & 1.30 & 5.18 & 0.007 \\
\hline Killip II or III & 0.41 & 0.09 & 1.89 & NS \\
\hline Cardiogenic shock & 3.90 & 1.43 & 10.65 & 0.008 \\
\hline Recurrent ischemia & 1.82 & 0.66 & 5.04 & NS \\
\hline Thrombolysis & 1.44 & 0.67 & 3.06 & NS \\
\hline
\end{tabular}

cardiogenic shock (major odds ratio). In this model, the association of ventricular dysfunction with complete atrioventricular block was expressed by the presence of Killip IV (cardiogenic shock); Killip II or III did not have a significant association with the occurrence of complete atrioventricular block.

Table VI shows nonadjusted odds ratios of various types of block relative to the absence of any one of them, taking the reference category into account. The mortality rate of cases without any of the referred blocks was $9.4 \%$ (75 deaths in 979 cases of acute myocardial infarction, without any type of block).

Mortality due to complete atrioventricular block associated with anterior localization of the acute myocardial infarction was significantly higher than that associated with the inferior wall, although both were high: $90 \%$ vs. $31 \%$, $\mathrm{P}<0.005$.

Table VII provides an analysis of the adjusted chance of inhospital death associated with different types of block, estimated by the logistic model, including as variables, sex, age, localization of the acute myocardial infarction, heart failure, cardiogenic shock, atrial fibrillation, ventricular tachycardia, ventricular fibrillation, right ventricular infarction, pericarditis, recurrent ischemia (clinical or electrocardiographic criteria), and use of a thrombolytic agent. Left

\begin{tabular}{|c|c|c|c|c|}
\hline \multicolumn{5}{|c|}{$\begin{array}{l}\text { Table VI - Nonadjusted risk of inhospital death associated to with } \\
\text { acute myocardial infarct block (category of reference: absence of } \\
\text { any block) }\end{array}$} \\
\hline Block & $\begin{array}{l}\text { Odds } \\
\text { ratio }\end{array}$ & \multicolumn{2}{|c|}{ 95\% CI Limits } & $p$ \\
\hline LBB & 5.92 & 2.17 & 15.90 & 0.0005 \\
\hline RBB+LAHB & 4.56 & 1.84 & 11.10 & $<0.0001$ \\
\hline $\mathrm{RBB}^{1}$ & 2.63 & 0.57 & 10.44 & NS \\
\hline Any branch block ${ }^{2}$ & 4.41 & 2.43 & 7.97 & $<0.0001$ \\
\hline AVB $2^{\text {nd }}$ Mobitz I & 1.28 & 0.14 & 5.69 & NS \\
\hline CAVB & 7.95 & 3.94 & 16.01 & $<0.0001$ \\
\hline Any block 2,3 & 4.49 & 2.84 & 7.11 & $<0.0001$ \\
\hline \multicolumn{5}{|c|}{$\begin{array}{l}\text { RBB- right branch block; LAHB- left anterior hemiblock; LBB- left } \\
\text { branch block; PHB- posterior hemiblock; CAVB- complete atrioventri- } \\
\text { cular block; AVB- atrioventricular block. }{ }^{1} \text { Isolated. }{ }^{2} \text { Includes } 5 \text { cases } \\
\text { de RBB+PHB. }{ }^{3} \text { Includes } 3 \text { cases of AVB } 2{ }^{\text {nd }} \text { Mobitz II. }\end{array}$} \\
\hline
\end{tabular}




\begin{tabular}{|lcccc|}
\hline Table VII - Risk of inhospital death associated with acute myocardial \\
infarct block estimated by the logistic model
\end{tabular}

anterior hemiblock, not specified in that table, was associated with nonsignificant odds ratio of $0.98(95 \% \mathrm{CI}=0.21$, at 4.64).

Table VII provides a summary of the results of three logistic models, differing merely by the grouping or not of the various types of block. The model that included each block in a discriminate manner had a concordance of $87.2 \%$. The model that considered branch blockade as a group (any branch block) had a concordance of $87.1 \%$. The model that included any form of block had a concordance of $83.1 \%$ and approached cases with branch or atrioventricular block. The grouped analysis of block of the last two models was performed to potentiate statistical significance, because the frequency of some types of block was low. The odds ratio adjusted for each type of block presented in the Table VII is estimated in relation to the reference category in each case, the absence of the block under consideration, other variables included in the model being kept under control, namely: sex, age, localization of the acute myocardial infarction, left ventricular insufficiency, shock, atrial fibrillation, ventricular tachycardia, ventricular fibrillation, right ventricular infarction, pericarditis, recurrent ischemia, and use of a thrombolytic agent.

\section{Discussion}

A historical series ${ }^{13,19}$ of 250 patients with acute myocardial infarction admitted consecutively during the era before thrombolytic therapy, to the coronary unit of a hospital in Rio de Janeiro showed a higher incidence of left (9.2\%) and right $(6.4 \%)$ bundle branch block, right branch block + anterior left branch hemiblock (3.2\%), and complete atrioventricular block $(5.2 \%)$ than that reported in the present study; the difference was statistically significant for intraventricular block. Studies ${ }^{5,6}$ from the prethrombolytic era, report atrioventricular $2^{\text {nd }}$ and $3^{\text {rd }}$ degree block in $19 \%$ of acute inferior myocardial infarctions. Although in these cases, block in general is reversed by medical therapy, it has been associated with greater mortality, apparently related to a more extensive infarction and to greater left and right ventricular dysfunction ${ }^{4-6}$. It is still not clear how thrombolytic therapy affects the incidence and prognostic implications of atrioventricular block, which complicates acute inferior myocardial infarction ${ }^{5,20}$.

Some researchers have suggested that cardiac block following thrombolysis could be an indicator of successful reperfusion; Verstraete et al ${ }^{9}$ found a nonsignificant tendency to higher ratios of $2^{\text {nd }}$ and $3^{\text {rd }}$ degree atrioventricular block associated with rt-PA $(8 \%)$ versus streptokinase $(2 \%)$. They argued that these could be related to the more rapid rate of reperfusion in the first situation. On the other hand, because thrombolysis is is able to reduce the size of the infarction, it might be expected that such therapy decreases the incidence of block and the high associated mortality ${ }^{8}$.

The GUSTO study (41,021 patients) reported a lower rate of incidence of atrioventricular block of the $2^{\text {nd }}$ and $3^{\text {rd }}$ degrees in the t-PA group relative to streptokinase ( $7.3 \%$ vs $9.1 \%, \mathrm{P}<0.001)$. The published study discussed the hypothesis that rapid restoration of myocardial blood flow can improve morbidity: the greater efficiency for reaching patency of the artery related to the infarction of the accelerated tPA scheme is well documented ${ }^{21}$.

On the other hand, the GISSI- 2 study of 12,4900 patients did not find a significant difference between complete atrioventricular block in the t-PA group $(5.1 \%)$ versus the streptokinase group $(5.5 \%)^{22}$.

The GISSI-1 study ${ }^{23}$ reported similar incidences of complete atrioventricular block in the streptokinase group $(5 \%)$ and nonthrombolytic-treated controls (5.7\%), respectively; this study was one of the few to have explicit incidences in control and treated groups.

Clemmensen et al. ${ }^{24}$ found $13 \%$ of complete atrioventricular block in 373 acute inferior myocardial infarction patients who underwent reperfusion therapy in the TAMI study, an incidence similar to that related for a study ${ }^{25}$ using thrombolytic therapy. These patients with complete atrioventricular block had higher ratios of morbidity and mortality relative to those without block. The development of complete atrioventricular block was an important independent predictor of inhospital death; although the acute patency ratios of the artery related to the infarct were similar in cases with or without complete atrioventricular block: the reoclusion ratio of this artery was greater in block cases ( $29 \%$ vs $16 \%, \mathrm{P}=0.03)$.

In a multicenter study ${ }^{7}$, comparing two cohorts of cases of acute myocardial infarction of the prethrombolytic $(n=7,788)$ and thrombolytic $(n=300)$ eras, Harpaz et al. described a significantly lower incidence of complete atrioventricular block in the latter (3.7\% vs. $5.3 \%)$. Nevertheless, multivariate analysis showed that the incidence of complete atrioventricular block was not reduced by the use of a thrombolytic agent and that also thrombolysis was an independent factor for a greater risk of the development of complete atrioventricular block (odds ratio=2.06). Other factors associated, in an independent manner, with the risk of complete atrioventricular block were advanced age, 
feminine sex, inferior localization of the infarction, and ventriallardysfunction (expressedbyK illipclass $\geq$ II).

On comparison with the study of Harpaz et al. ${ }^{7}$ our results showed a higher incidence of complete atrioventricular block $(4.5 \%)$ with thrombolytic therapy, and agreed regarding a significant association with inferior localization of the infarction and ventricular dysfunction; in regard to the use of thrombolytic drugs, Harpaz et al. only showed a nonsignificant tendency toward a positive association with complete atrioventricular block. Both studies showed that mortality associated with the development of complete atrioventricular block remained high with thrombolytic therapy.

A hypothesis presented by Harpaz et al. was that patients with a greater extension of lack of ST level would have a greater probability of receiving thrombolytics as well as having a larger infarction and a greater probability of developing complete atrioventricular block ${ }^{7}$.

Reports of branch block with thrombolytic therapy are even scantier and are generally limited to the characteristics of the electrocardiogram required during hospitalization. Melgarejo-Moreno et al. in a multicenter study of 1238 consecutive cases of acute myocardial infarction ${ }^{11}$ described a $10.9 \%$ frequency of right branch, isolated or associated with hemiblock; $37.8 \%$ of the blocks were acute, $34.1 \%$ previous to acute myocardial infarction, and $26.1 \%$ of indeterminate duration. In our study, the frequency of all forms of right branch block (isolated or associated) was smaller (5.1\%), with a higher proportion of acute block $(54.6 \%)$ and a lower proportion of previous occurrence $(19.1 \%)$. That multicenter study showed that the presence of right branch block was an independent indicator of worse diagnosis concerning inhospital mortality and follow-up during the first year.

Melgarejo-Moreno et al. ${ }^{26}$ in another study described an incidence of $3.3 \%$ of left branch block in acute myocardial infarction, slightly higher than that observed in the present study (2.3\%).

Newby et al. ${ }^{10}$ in 681 patients recruited in TAMI- 9 and Gusto-1, monitored by Holter, described a general incidence of any right branch block (isolated or associated) of 13\%, left branch of $7 \%$, and alternating of $3.5 \%$. Patients with left branch block showed lower ejection fraction, higher CPK peaks $(\mathrm{p}<0.001)$, and greater vessel involvement $(\mathrm{p}<0.02)$ compared with those free of block. Compared with our results, the higher frequency of the branch block observed by these authors may be connected to the use of Holter moni- toring; only $22.4 \%$ of the cases of branch block described were persistent. In their study, the presence of persistent branch block was also shown to be a predictor of high mortality compared with to transitory or absent block.

In the present study, the percentage of use of thrombolysis was low. Harpaz et al. ${ }^{7}$ reported use of $47.5 \%$, Melgarejo-Moreno et al. ${ }^{11,20}$ mentioned 55\%. Despite these differences in the use of thrombolysis, our results agreed with those cited concerning a more reserved prognosis of patients evolving to branch or complete atrioventricular block. Regarding incidence, the most marked difference was due to the higher occurrence of right branch block shown by Melgarejo-Moreno et al. ${ }^{11}$.

Many authors refer to the thrombolytic era as having been initiated by the introduction of intravenous thrombolysis; variations in the percentage use of this therapy have been described worldwide. A multicenter North American study reported use of only $30 \%{ }^{27}$, an English one of $48 \%{ }^{28}$. Another aspect to be considered is the incorporation of other pharmacological and non-pharmacological interventions in present treatment of myocardial infarction; this certainly introduces an additional factor of complexity into the analysis of the so-called thrombolytic era; it deserves further investigation.

In conclusion, for the population studied during the thrombolytic era, the observed frequency of intraventricular conduction disturbance was lower than that reported by the same coronary unit in studies in the prethrombolytic era.

The logistic regression showed a greater probability of the incidence of bundle branch block associated with the male sex, with age above over 70 with anterior infarct localization, and with left ventricular insufficiency. Variables associated with a greater incidence of complete atrioventricular block were inferior localization of the infarction and presence of cardiogenic shock. The percentage of use of thrombolytics was low over the period of study (19.3\%) and associated with a nonsignificant tendency towards a lower occurrence of bundle branch block and a higher occurrence of complete atrioventricular block.

In summary, both the presence of bundle branch block as well as of complete atrioventricular block were associated with a high and independent probability of inhospital death in a multivariate model that included the use of thrombolytics. Therefore, intraventricular conduction disturbances (analyzed as a group) and complete atrioventricular block remain important predictors of a poor prognosis in the thrombolytic era. 


\section{References}

1. Nimetz AA, Shubrooks SJ, Hutter AM, DeSanctis RW. The significance of bundle branch block during acute myocardial infarction. Am Heart J 1975; 90: 439-44.

2. Hindman MC, Wagner GS, JaRo M, et al. The clinical Significance of Bundle Branch Block Complicating Acute Myocardial Infarction 1. Circulation 1978; 58: 679-88.

3. Nicod P, Gilpin E. Dittrich H, Polikar R, Henning H, Ross J. Long-term outcome in patients with inferior myocardial infarction and complete atrioventricular block. J Am Coll Cardiol 1988; 12: 589-94.

4. Bassan R, Maia IG, Bozza A, Amino JGC, Santos M. Atrioventricular block in acute inferior wall myocardial infarction: harbinger of associated obstruction of the left anterior descending coronary artery. J Am Coll Cardiol 1986; 8: 773-8.

5. Berger PB, Ryan TJ. Inferior infarction: high risk subgroups. Circulation 1990; 81: 401-11.

6. Archbold RA, Sayer JW, Ray S, Wilkinson P, Ranjadayalan K, Timmis AD. Frequency and prognostic implications of conductions defects in acute myocardial infarction since the introduction of thrombolytic therapy. Eur Heart J 1998; 19: 893-8.

7. Harpaz D, Behar S, Gottlieb S, Boyko V, Kishon Y, Eldar M, et al for the SPRINT Study Group. Complete atrioventricular block complicating acute myocardial infarction in the thrombolytic era. J Am Coll Cardiol 1999; 34: 1721-8.

8. O'Rouke M, Baron D, Keogh A, et al. Limitation of myocardial infarction by early infusion of rtPA. Circulation 1988; 77: 1311-5.

9. Verstraete M, Bory M, Collen D, etal. Randomized trial of IV rtPA x IV SK. Lancet 1985; $1: 842-7$.

10. Newby KH, Pisano E, Krucoff MW, Green C, Natale A. Incidence and clinical relevance of the occurrence of bundle-branch block in patients treated with thrombolytic therapy. Circulation 1996; 94: 2424-8.

11. Melgarejo-Moreno A, Galcera-Tomas J, Garcia-Alberola A, et al. Incidence, clinical characteristics and prognostic significance of right bundle-branch block in acute myocardial infarction: a study in the thrombolytic era. Circulation 1997; 96: 1139-44.

12. Sgarbossa EB, Pinski SL, Topol EJ, et al. Acute myocardial infarction and complete bundle branch block at hospital admission: clinical characteristics and outcome in the thrombolytic era. GUSTO-1 Investigators. Global Utilization of Strpeokinase and t-PA for Occluded Coronary Arteries. J Am Coll Cardiol 1998; 31: $105-10$.

13. Escosteguy CC, Carvalho, MA, Abreu LM. Análise da ocorrência e letalidade associada a distúrbios de condução intra e atrioventriculares no infarto agudo do miocárdio: era pré e pós-trombolítica. Revista da SOCERJ 1995; vol.VIII(supl A): 21 .

14. The Criteria Commitee of the New York Heart Association. Diseases of the Heart and Blood Vessels. Nomenclature and Criteria for Diagnosis. Sixth Edition. Boston: Little Brown, 1964; 421
15. Pedoe-Tunstall H, Kuulasmaa K, Amouyel P, Arveiler D, Rajakangas AM, Pajak A for the WHO MONICA Project. Myocardial infarction and coronary deaths in the World Health organization MONICA project. Circulation 1994; 90: 583-612

16. Rosenbaum MB, Elizari MV, Lazzari J. Los Hemibloqueios. Buenos Aires: Ed. Paiolos, 1967

17. Rosenbaum MB. Types of left bundle branch block and their clinical significance. J Electrocardiology 1969; 2: 197-206.

18. Consenso Brasileiro sobre Trombólise. Diretrizes da Sociedade Brasileira de Cardiologia sobre cuidados ao paciente infartado. Arq Bras Cardiol 1994; 63(II): $1-8$

19. Carvalho MA, Sales LMC, Bezerra MG, Carneiro RD. Distúrbios de condução atrioventricular e auriculoventricular no infarto agudo do miocárdio. In: Carvalho MA, Carneiro RD, eds. Infarto do Miocárdio e suas Complicações. Rio de Janeiro: Bloch Editores, 1976: 78-83.

20. Berger PB, Ruocco NA, Ryan TJ, Frederick MM, Jacobs AK, Faxon DP e TIMI Investigators. Incidence and prognostic implications of heart block complicating inferior myocardial infarction treated with thrombolytic therapy: results from TIMI II. J Am Coll Cardiol 1992; 20: 533-40.

21. GUSTO (Global Utilization of Streptokinase \& Tissue Plasminogen Activator for Occluded Coronary Arteries) Investigators. An international randomized trial comparing four thrombolytic strategies for acute myocardial infarction. $\mathrm{N}$ Engl J Med 1993; 329: 673-82.

22. GISSI 2. A factorial randomised trial of alteplase versus streptokinase and heparin versus no heparin among 12490 patients with acute myocardial infarction. The Lancet 1990; 336: 65-71.

23. GISSI (Gruppo Italiano Per Lo Studio della Streptochinase Nell'Infarto Miocardico). Effectiveness of intravenous thrombolytic treatment in acute myocardial infarction. The Lancet 1986; i: 397-401.

24. Clemmensen P, Bates ER, Calliff RM, et al. Complete atrioventricular block complicating inferior wall acute myocardial infarction treated with reperfusion therapy. TAMI Study Group. Am J Cardiol 1991; 67: 225-30.

25. ISAM Study Group. A prospective trial of intravenous thrombolytic treatment in acute myocardial infarction. N Engl J Med 1986; 314: 1465-71.

26. Melgarejo-Moreno A, Galcera-Tomas J, Garcia-Alberola A, et al. The incidence, clinical characteristics and prognostic significance if a left bundle-branch block associates with an acute myocardial infarction. Rev Esp Cardiol 1999; 52: 245-52.

27. McGovern PG, Pankow JS, Shahar E, et al. Recent trend in acute coronary heart disease. Mortality, mordidity, medical care and risk factors. N Engl J Med 1996; 334: 884-90.

28. Brown N, Youg T, Gray D, Skene AM, Hampton JR. In patients deaths from acute myocardial infarction, 1982-92: analysis of data in the Nottingham heart attack register. Br Med J 1997; 315: 159-64. 